\title{
Augmentation of the coagulation activity of alum using a porous bio-flocculant for the remediation of trihalomethanes-generating hydrophobic natural organic matter
}

\author{
Bramha Gupta, Tanwi Priya, Brijesh Kumar Mishra ${ }^{\dagger}$ \\ Department of Environmental Science and Engineering, Indian Institute of Technology (Indian School of Mines), Dhanbad-826004, India
}

\begin{abstract}
Conventional coagulation techniques have shown inefficacy for the removal of DBPs precursor i.e. hydrophobic NOM. The present study has used a bio-flocculant named Ficus benghalensis to enhance the coagulation activity of alum for the removal of hydrophobic NOM. The coagulation activity of the augmented treatment (Alum-F. benghalensis) system was validated using spectroscopic analysis. The augmented system had shown an increment in DOC and $A_{254}$ removal by $\sim 30 \%$ and $\sim 16 \%$, respectively. ASI and $A_{272}$ had shown a continual decrease (from 0.12 to 0.08 and 0.46 to 0.23 , respectively) for the augmented system. Chlorine demand was found lesser for the augmented system $(1.4 \mathrm{mg} / \mathrm{L})$ compared to alum $(1.55 \mathrm{mg} / \mathrm{L})$ only. The augmented system had shown a drastic reduction (from 0.1459 to 0.0638$)$ in the value of $\left(-\Delta \mathrm{A}_{272}\right)$, which is directly related to the reduction in THMFP. The combined effects of sweep coagulation and charge neutralization were the responsible mechanisms for the augmented coagulation system. The noteworthy anti-bacterial activity of $F$. benghalensis was observed due to the presence of silver, copper, and traces of chlorine in its structure. Thus, the proposed augmented coagulation system can be used to remove the hydrophobic NOM from the water.
\end{abstract}

Keywords: Anti-bacterial activity, Augmented coagulation, Bio-flocculant, Natural organic matter, Spectral indices, Trihalomethane formation potential

\section{Introduction}

The occurrence of natural organic matter (NOM) in the surface water due to the disposal of surface runoff, soil leachate, agricultural waste, industrial waste, and domestic sewage has increased the organic load in surface water [1-3]. NOM is defined as heterogeneous mixture of humic (hydrophobic/aromatic) and non-humic (less hydrophobic/aliphatic) organic components [4]. The hydrophobic fraction of NOM has shown its reactivity towards disinfectants such as chlorine, ozone, chlorine dioxide to form carcinogenic and genotoxic disinfectant by-products [5-7]. According to literature, hydrophobic fractions (humic acid and fulvic acid) of NOM have a prominent contribution to dissolved organic carbon (DOC) in water. These DOC in water will form disinfectant by-products (DBPs) such as trihalomethanes (THMs), haloacetonitriles $\left(\mathrm{HAN}_{\mathrm{S}}\right)$, haloketones $(\mathrm{HKs})$, chloral hydrate $(\mathrm{CH})$, chloropicrin (CP), and halo acetic acid (HAA) in chlorinated water [8-10].
Literature depicts that NOM goes through substitution/oxidation reaction (during chlorination) with hypochlorous acid (HOCl) to form organic-halide compounds like THM and HAA [11-17]. THM is one of the most prominent DBPs in surface water, as it has adverse carcinogenic and non-carcinogenic risks and detrimental effects on human health as well as it adds about $20 \%$ of total DBPs [10, 18-20].

Coagulation and adsorption are effective remediation approach for the removal of THMs surrogates, aromatic NOM, in order to control the chlorinated by-products formation in drinking water [21]. Coagulation is described as "the destabilization of negatively charged colloidal and suspended particles dispersed in water using coagulating agents", has been considered as suitable technique for the removal of high molecular weight as well as negatively charged colloidal particles from water [21]. These coagulating agents have been categorized as metallic salts (alum, ferric salts, zirconium oxychloride, and titanium tetrachloride), synthetic organic polymers (polyaluminium chloride), natural coagulants (Castenea
This is an Open Access article distributed under the terms of the Creative Commons Attribution Non-Commercial License (http://creativecommons.org/licenses/by-nc/3.0/) which permits unrestricted non-commercial use, distribution, and reproduction in any medium, provided the original work is properly cited.

Copyright (C) 2021 Korean Society of Environmental Engineers
Received May 13, 2020 Accepted July 19, 2020

${ }^{\dagger}$ Corresponding author

Email: bkmishra3@rediffmail.com

Tel: +919471191704

ORCID: 0000-0002-4451-1924 
Sativa, Moringa oleifera, Strychnos potatorum, and Cassia jahavikai), natural polymers (corn starch, paddy starch, elastin, and collagen), and natural polymer derivatives chitosan (N-deacetylated derivative of chitin) [10, 22-29]. The intricate structure, partial biodegradation, and low solubility of synthetic organic polymers have made it unsuitable as a coagulant [22, 30]. Even though, alum has been the most preferred coagulant across the globe owing to its low cost, easy availability, and its less sludge production than lime and ferrous salt, but it might exhibit few disadvantages like increment in dissolved solids, overdosing causes human risks like Alzheimer's disease, the formation of huge amounts of sludge compares to natural coagulant, and less removal of NOM [23].

The extracts of natural coagulants are being used nowadays as bio-flocculant to enhance the coagulation activity of the inorganic coagulants. Although, the use of natural coagulants is economical and effective remediation approach for the treatment of high turbid water [25, 26]. But, the organic matrix of biomass tissues, microorganisms, and animal extracts such as polysaccharides, protein, and nucleic acid tends to increase the organic load in water [31]. The low coagulation activity of natural coagulants in the reduction of turbidity of low turbid water has been validated by several researchers [26]. Even the removal efficiency of natural coagulants can be raised by reducing organic contents from its extract by the ion-exchange process [32]. Still, it is considered as a practical approach for field application. Due to organic nature and low coagulation activity of natural coagulant in low turbid water, a new approach, i.e., enhanced coagulation (or augmented coagulation), could be used to study the variation in characteristics of colloidal impurities dispersed in water.

In recent years, augmented coagulation has proved a well-optimized process as it has increased the removal efficiency of inorganic coagulants. The mutual effects of sweep coagulation and precipitate charge neutralization are the responsible mechanisms for the augmented coagulation [33]. Generally, bio-flocculant [i.e., Moringa oleifera, Cyamopsis tetragonoloba] causes an increment in total organic carbon (TOC) whereas, TOC depends upon molecular weight and the active component of organic carbon. ASI and $\mathrm{A}_{272}$ have a linear relation with DOC and active aromatic groups, respectively, that are responsible for trihalomethanes formation potential (THMFP) [10, 34-36] and showed a continual decrease from the conventional coagulation to augmented coagulation process.

The noteworthy research gaps for the current study are the limitations of alum as a coagulant (i.e., increment in dissolved solids, overdosing causes Alzheimer's disease, huge sludge production than natural coagulants, etc.) for the removal of aromatic NOM (surrogates of THMs), low coagulation activity of natural coagulants while its suitability as bio-flocculant to treat THM's surrogates, assessment of THMFP using spectral indices, etc. These gaps are addressed in the current study. Considering the limitations of alum and natural coagulants, an augmented system has been proposed, which showed better suitability for the removal of active aromatic NOM fraction and ultimate THMFP reduction.

In the present study, the coagulation activity of alum is augmented using a bio-flocculant named Ficus benghalensis (or F. benghalensis) for the removal of turbidity and NOM surrogates [DOC, UV-absorbance at $272 \mathrm{~nm}\left(\mathrm{~A}_{272}\right)$, and specific UV-absorbance (SUVA)]. The effects of various influencing parameters on coagulation activity were also assessed. The NOM consumption by chlorination process was further validated using spectral indices (i.e., $\mathrm{A}_{272}$, ASI, and $\left.-\Delta A_{272}\right)$. The spectroscopy and microscopy analysis were carried out to get the physiochemical attributes of the coagulants. Anti-bacterial assay of $F$. benghalensis was also carried out to get the zone of inhibition, which corresponds to the presence of disinfectants like silver, copper, and chlorine in its structure. The proposed augmented coagulation system can be widely used to remove the hydrophobic NOM from water.

\section{Experimental}

\subsection{Chemicals}

Aluminum sulphate $\left[\mathrm{Al}_{2}\left(\mathrm{SO}_{4}\right)_{3} \cdot 18 \mathrm{H}_{2} \mathrm{O}\right]$ commonly known as "alum", sodium hypochlorite $(\mathrm{NaOCl})$, sodium hydroxide $(\mathrm{NaOH})$, hydrochloric acid (HCl), and starch were purchased from Merck, India. Humic acid and kaolin were purchased from Loba Chemie, India. F. benghalensis seeds were supplied by Sun Seeds Pvt. Ltd., India. All the chemicals were of analytical grades.

\subsection{Reagents Preparation}

The alum solution was prepared by dissolving $1 \mathrm{~g}$ of alum in $1 \mathrm{~L}$ of deionized water. Synthetic water enriched with NOM was prepared using humic acid solution and kaolin as per the reported method [24, 37, 38]. The predetermined $\mathrm{pH}$ and turbidity of synthetic water were adjusted using $0.1 \mathrm{~N} \mathrm{HCl} / \mathrm{NaOH}$ and kaolin, respectively.

Collected seeds of $F$. benghalensis were dried and grounded into powder form using a blender. Active components of $F$. benghalensis were extracted by mixing $1 \mathrm{~g}$ of coagulant powder in 1 $\mathrm{L}$ of deionized water (Millipore, Germany). The solution was stirred at $20 \mathrm{rpm}$ for 20 minutes in magnetic stirrer (Tarsons, India) [10]. Coagulant solution was further filtered through filter paper (42 No., Whatman Int. Ltd, England). Freshly prepared F. benghalensis solution was preserved and used for coagulation.

\subsection{Cultural Media Preparation for the Anti-Bacterial Test}

The set nutritional agar (HI media) petri plates were dried at $37^{\circ} \mathrm{C}$ in a laminar air flow chamber under UV light and inoculated with stock Escherichia coli ATCC 25922 (American Type Culture Collection, Rockville, MD). Stock Escherichia coli ATCC 25922 was used due to its suitability for antibiotic susceptibility assays. The inoculated plates had three $6 \mathrm{~mm}$ diameter cut-outs on Whatman filter paper into the surface of the agar. The cut-outs were dipped with $F$. benghalensis solution, and all plates were incubated $\left(34^{\circ} \mathrm{C}\right)$ overnight [39]. After incubation, the zone of inhibition was measured by calculating its diameter with the help of calipers.

\subsection{Jar Test}

Jar test apparatus (Scientific Engineering Corp., India) was used for the coagulation experiment. During coagulation, synthetic water was placed in four paddled jars. For simple coagulation, alum was added, and the solution was subjected to rapid mixing at $200 \mathrm{rpm}$ for $2 \mathrm{~min}$, followed by slow mixing for $40 \mathrm{rpm}$ for $15 \mathrm{~min}$ under suitable operational conditions. Whereas, for augmented 
Table 1. Experimental Conditions

\begin{tabular}{lcc}
\hline Sr. No. & Parameters & Value/Conditions \\
\hline 1 & $\mathrm{pH}$ & 6 \\
2 & $\mathrm{Dose}$ & $2 \mathrm{mg} / \mathrm{L}$ alum and $1-4 \mathrm{mg} / \mathrm{L} \mathrm{F}$. benghalensis \\
3 & Initial TOC & $25.76 \mathrm{mg} / \mathrm{L}$ \\
4 & Initial DOC & $24.5 \mathrm{mg} / \mathrm{L}$ \\
5 & Initial turbidity & $10 \mathrm{NTU}$ \\
6 & Temperature & Room temperature \\
7 & Time & 2 min rapid mixing, 15 min slow mixing, and 30 min settling. \\
8 & Mixing conditions & $200 \mathrm{rpm}$ for rapid and $40 \mathrm{rpm}$ for slow mixing in jar apparatus. \\
\hline
\end{tabular}

coagulation, defined doses of alum added as a primary coagulant and allowed for rapid mixing, further a predetermined doses of $F$. benghalensis was added during slow mixing to increase the flocculation activity. Flocs were allowed to form by placing the sample in the steady state for $30 \mathrm{~min}$. After settling of colloidal particles, the samples were collected with the help of a syringe in the plastic bottles for the quality analysis. The test conditions during the experimentation are given in Table 1 .

\subsection{Analysis}

The measurement of $\mathrm{pH}$, TOC, DOC, $\mathrm{A}_{254}$, SUVA, and chlorine demand was carried out as per the APHA standard protocols [40]. Zeta potential was analyzed by the zeta analyzer (Horiba Scientific, Nano Particle, Japan). TOC and DOC were measured using a high-temperature combustion infrared method (TOC analyzer, Shimadzu, Japan). Samples were filtered through $0.45 \mu \mathrm{m}$ nitrocellulose membrane before DOC and spectral analysis. Turbidity and $\mathrm{pH}$ were measured using a Digital turbidity meter (E.I., India) and bench-scale $\mathrm{pH}$ meter (Hanna Instruments, Germany), respectively. Analysis of various spectral indices $\left(\mathrm{A}_{254}, \mathrm{ASI}\right.$, and $A_{272}$ ) was conducted using a UV-Vis spectrophotometer (Lab-tech, China). The significance of different spectral indices has been shown in Table 2. Differential spectroscopy $\left(-\Delta \mathrm{A}_{272}\right)$ with reference to chlorine consumption for the treated water was carried out as per the reported method [41]. All the experiments were conducted in triplicate for reproducibility purposes.

X-ray diffraction (XRD) (Ultima IV, Rigaku, Japan) and Fourier transform infrared spectroscopy (FTIR) (Agilent Technology) analysis were conducted as per reported methods [42]. Similarly, morphological characteristics of the coagulant and agglomerates were examined using field-emission scanning electron microscopy (FE-SEM)
(Zeiss, Germany). The anti-bacterial assay was conducted to study the disinfection property of the coagulant.

\section{Results and Discussion}

Although F benghalensis is not an efficient coagulant, it is useful as a bio-flocculant. In this work, the main focal point is on augmented coagulation using $F$. benghalensis as bio-flocculant based on percentage removal of turbidity and NOM surrogates, and assessment of spectral indices. Before elaborating on the performance of $F$. benghalensis as a coagulant and bio-flocculant, the physiochemical characterization was carried out to know the chemical reactions involved during the coagulation process. The antibacterial activity of $F$. benghalensis was also assessed to validate the presence of disinfectants like silver, copper, and chlorine in it. The detailed study, including physiochemical properties and performance of the $F$ benghalensis as a bio-flocculant, has been discussed as follows.

\subsection{Physiochemical Characterizations of Powdered Seeds and Sludge of $F$. benghalensis (bio-flocculant)}

The speciation of functional groups present in $F$. benghalensis is shown in Fig. 1 (a). The spectral range of 1,600-1,800 $\mathrm{cm}^{-1}$ corresponds to the $\mathrm{C}=\mathrm{O}$ bond stretching and carbonyl group present in the protein and fatty acid structures [10, 43, 44]. The peak at $1,610.27 \mathrm{~cm}^{-1}$ shows the presence of aromatic C-C and C-H bonds, and the peak at $2,925.48 \mathrm{~cm}^{-1}$ shows the symmetric and asymmetric stretching of the C-H group present in fatty acid [45]. The presence of carbonyl group, fatty acid, protein, and alkyl group validated that $F$. benghalensis contains organics in its matrix.

Table 2. Physical Parameters

\begin{tabular}{|c|c|c|}
\hline Parameters & Significance & References \\
\hline SUVA $\left(\mathrm{A}_{254} * 100 / \mathrm{DOC}\right)$ & Shows aromatic content mainly hydrophobic fraction of NOM. & [19] \\
\hline $\mathrm{A}_{254}$ & Shows the qualitative nature DOC and responsible for THM formation & [9] \\
\hline $\begin{array}{l}\text { ASI } \\
{\left[0.56\left(\mathrm{~A}_{254}-\mathrm{A}_{272}\right) /\left(\mathrm{A}_{220}-\mathrm{A}_{230}\right)\right]}\end{array}$ & $\begin{array}{l}\text { Similar to DOC, ASI values decrease consistently in coagulated waters \& correlated with } \\
\text { THMFP and chlorine demand. }\end{array}$ & {$[34]$} \\
\hline $\mathrm{A}_{272}$ & Shows the activated aromatic groups of DBPFP. & [35] \\
\hline$-\Delta \mathrm{A}_{272}$ & $-\Delta \mathrm{A}_{272}$ has a definite correlation with DBP formation at different chlorine doses & {$[41,57]$} \\
\hline
\end{tabular}



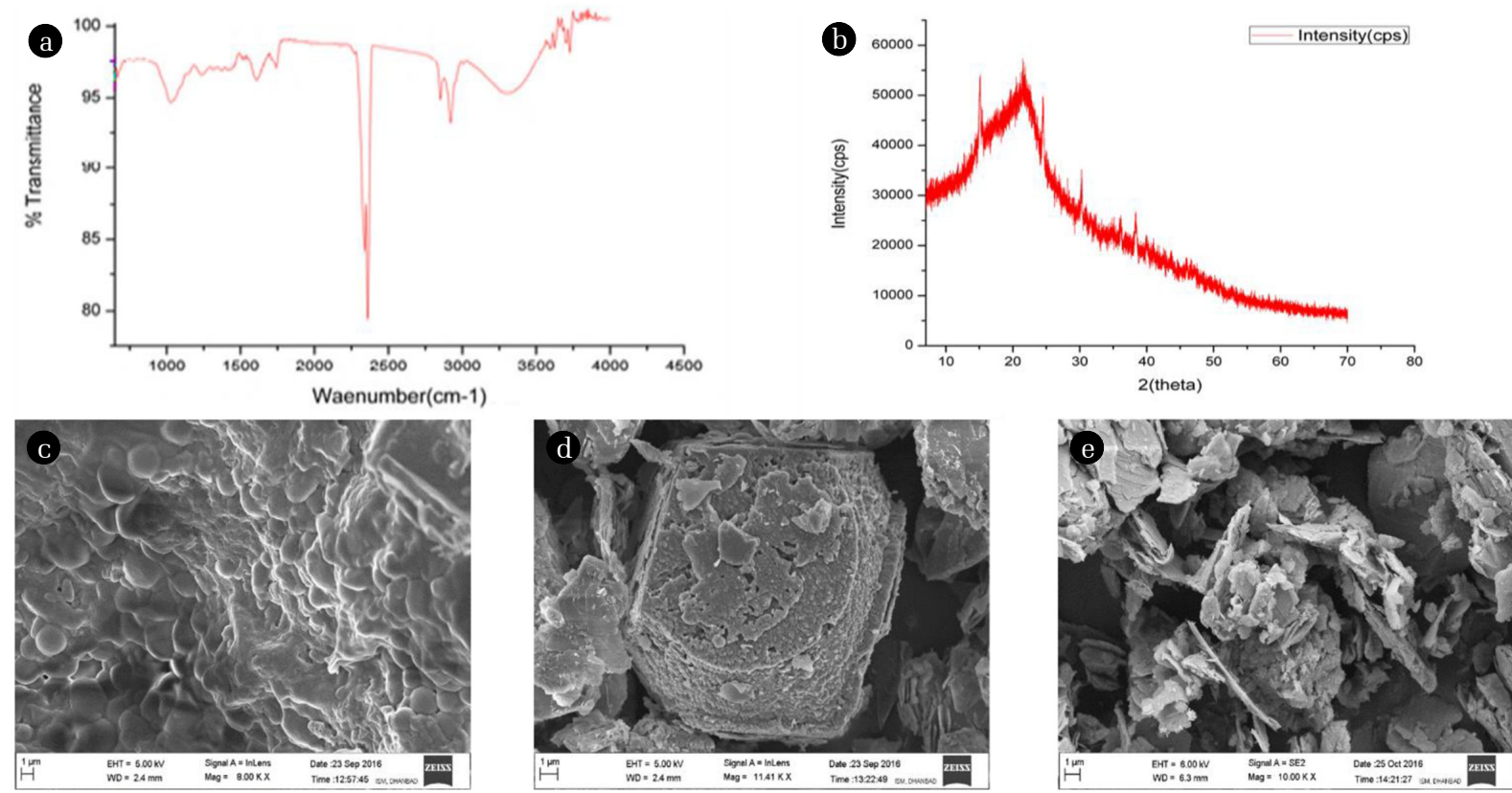

Fig. 1. (a) FTIR graph of $F$. benghalensis (powder). (b) X-ray diffractogram of $F$. benghalensis. FE-SEM image of (c) $F$. benghalensis powder, (d) sludge of $F$. benghalensis treated water, and (e) treated agglomerate of Alum- $F$. benghalensis.

The X-ray diffractogram of $F$. benghalensis has been shown in Fig. 1 (b). The poorly resolved peaks indicate the amorphous nature due to the presence of protein, lipids, and unsaturated fatty acid in F benghalensis. The crystalline region of coagulant is possibly due to diffraction of protein around the particles having a more amorphous structure; this behavior is evident since non-skewed $F$. benghalensis seed was used [46]. The XRD diffractograms show the presence of minerals such as Freedite $\left(\mathrm{Pb}_{8} \mathrm{Cu}\left(\mathrm{AsO}_{3}\right)_{2} \mathrm{O}_{3} \mathrm{Cl}_{5}\right)$ and Jalpaite $\left(\mathrm{Ag}_{3} \mathrm{CuS}_{2}\right)$. The presence of silver $(\mathrm{Ag})$, copper $(\mathrm{Cu})$, and $\mathrm{Cl}$ (chlorine) elicit anti-bacterial characteristics of $F$. benghalensis, which is further validated in the anti-bacterial study [9, 47, 48].

The FE-SEM micrograph of $F$. benghalensis powder and its agglomerates are shown in Fig. 1 (c), (d). The FE-SEM image of $F$. benghalensis represents the globular and porous structure. The honeycomb structure of $F$. benghalensis [Fig. 1 (d)] of treated agglomerate shows that the sweep coagulation as a possible mechanistic approach for $F$. benghalensis mediated coagulation process [49]. The FE-SEM analysis of alum-F. benghalensis (augmented coagulation) treated agglomerates are shown in Fig. 1 (e), which represents the dispersed flocs over the plate-like structure. These results suggest that the synchronized effects of charge neutralization and sweep coagulation are the driving force for augmented coagulation using alum-F. benghalensis [49].

\subsection{Anti-Bacterial Activity of F. benghalensis Powder}

In the present study, the anti-bacterial activity of $F$. benghalensis powder was carried out, and the result was compared with chlorine based on the zone of inhibition (Table 3).

The result suggetes that zone of inhibition increased linearly with concentration initially, but the diameter of the zone of inhibition decreased after $250 \mathrm{mg} / \mathrm{L}$ and $10 \mathrm{mg} / \mathrm{L}$ concentration for
F. benghalensis and chlorine, respectively. These results showed a dip due to the increase in molecular distribution that yields several interactions in nearby polymeric chains. Lower concentration probably promotes higher mobility of moieties and availability of more charged sites for external coupling due to less interaction between polymeric chains [50]. But at higher concentration, hydrogen bonds and covalent bonds might be formed between the functional groups of $F$. benghalensis, leading to densely overlapping coils formation around it, which eventually restrict its interfacial interaction. Consequently, an inferior number of charged sites would be available for interaction, which could affect the binding to bacterial cell walls [51, 52]. Thus, it could be interpretated that high concentration of disinfectant might affect the zone of inhibition. Thus, the maximum inhibition concentration (MIC) will be $250 \mathrm{mg} / \mathrm{L}$ and $10 \mathrm{mg} / \mathrm{L}$ for $F$. benghalensis and chlorine, respectively. The significant anti-bacterial activity of $F$. benghalensis is due to the presence of various anti-bacterial agents like silver, copper, and chlorine in its structure, as discussed in XRD analysis. Similarly, Priya et al. [10] have reported the anti-bacterial activity of the natural coagulants, such as M. oleifera and C. tetragonoloba.

Table 3. The Diameter of the Zone of Inhibition at Various Concentrations

\begin{tabular}{lcc}
\hline $\begin{array}{l}\text { Concentration } \\
(\mathbf{m g} / \mathbf{L})\end{array}$ & $\begin{array}{c}\boldsymbol{F} \text {. benghalensis dia. } \\
(\mathbf{m m})\end{array}$ & $\begin{array}{c}\text { Chlorine dia. } \\
(\mathbf{m m})\end{array}$ \\
\hline 2.5 & 0.67 & 0.375 \\
5 & 1.34 & 0.83 \\
7.5 & 1.5 & 1.66 \\
10 & 1.67 & 1.9 \\
250 & 3 & 1.4 \\
500 & 2.67 & 1.55 \\
\hline
\end{tabular}


Based on the physiochemical and anti-bacterial study, it could be assumed that the $F$. benghalensis has the potential to act as bio-flocculant to augment the coagulation activity of the alum for the removal of hydrophobic NOM. In the subsequent sections, the performance of the augmented coagulation system has been tested for the removal of hydrophobic NOM and validated using spectral indices.

\section{3. $\mathrm{pH}$ Optimization and Validation}

The dependency of the coagulant activity of the augmented coagulation system on the $\mathrm{pH}$ of the water has been assessed at a constant coagulant dose (alum: $2 \mathrm{mg} / \mathrm{L}$ and F. benghalensis: $1 \mathrm{mg} / \mathrm{L}$ ). Usually, slightly alkaline $\mathrm{pH}$ favors the flocculating activity of natural coagulants. But, in the case of $F$. benghalensis, it has shown high efficiency at $\mathrm{pH}$, which may be due to the presence of oxide

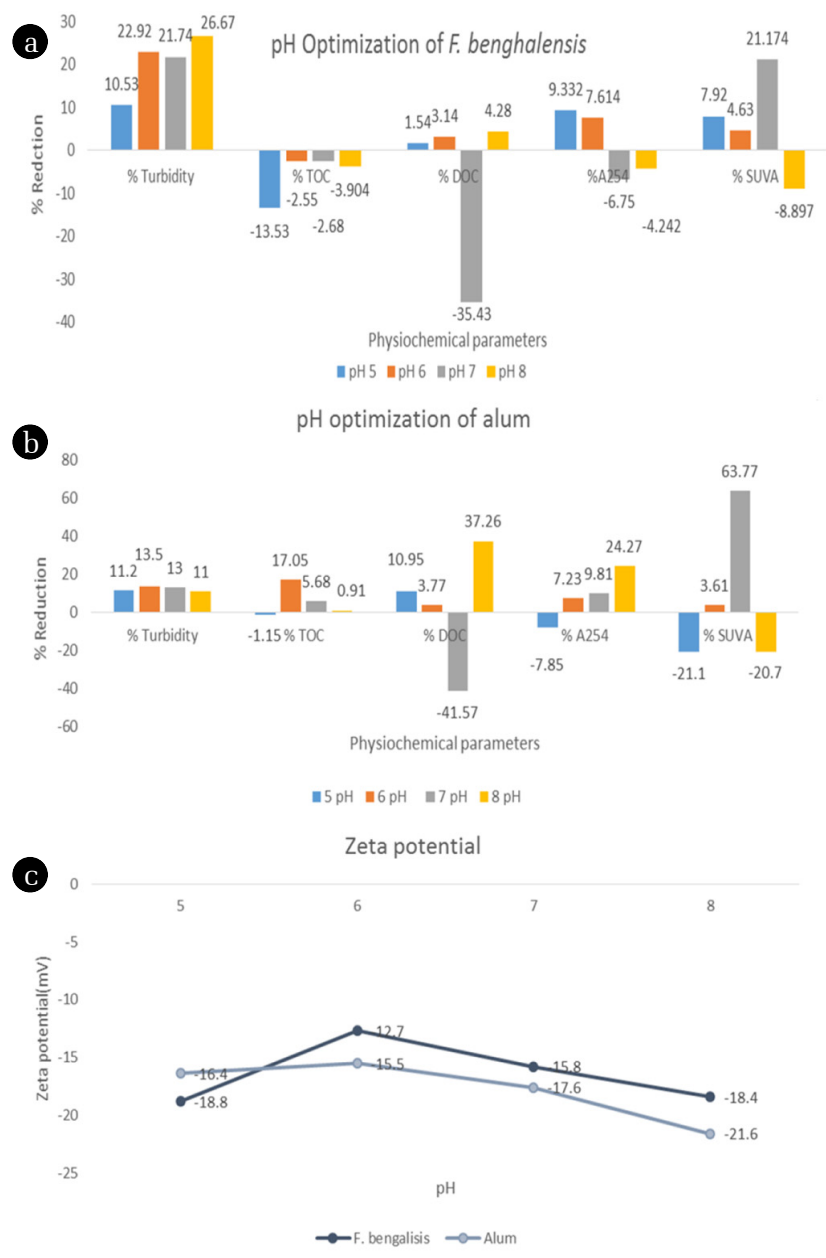

Fig. 2. (a) $\mathrm{pH}$ optimization of $F$. benghalensis. (b) $\mathrm{pH}$ optimization of alum. (c) Zeta potential of $F$. benghalensis and alum. and sulfide of metals, as shown by the XRD analysis. Researchers have already validated that alum worked efficiently in slightly acidic conditions [53]. In the present study, it was observed that F. benghalensis and alum exhibited maximum removal of turbidity and NOM surrogates (i.e., TOC, DOC, $\mathrm{A}_{254}$, and SUVA) at $\mathrm{pH} 6$ [Fig. 2 (a) and (b)], because the zeta potential is very close to zero at pH 6 [Fig. 2 (c)] for both alum and F. benghalensis, respectively. Results suggested that synchronized impact of alum (primary coagulant) and $F$. benghalensis (bioflocculant) exhibited optimum coagulant activity for the removal of the NOM surrogates (i.e., TOC, DOC, SUVA, and $\mathrm{A}_{254}$ ) and turbidity at $\mathrm{pH} 6$.

Zeta analysis was performed to validate the optimum $\mathrm{pH}$ [Fig. 2 (c)] as a function of variation in surface charge of the colloidal particles. In Fig. 2 (c), zeta potential tend to decrease from $\mathrm{pH}$ 5 to 6 due to better agglomeration and then increased at higher $\mathrm{pH}$ values due to less removal of negatively charged colloidal particles. At $\mathrm{pH} 6$, zeta potential values seemed very close to zero for both $F$. benghalensis and alum due to better removal of turbidity and NOM surrogates, so at this $\mathrm{pH}$, the colloidal particles will be in stable condition as maximum particles get stabilized, suggesting $\mathrm{pH} 6$ as optimized parameter.

\subsection{Physiochemical Parameters of the Source Water}

Synthetic water was prepared to have a resemblance to surface water enriched with aromatic NOM. The physiochemical characteristics of tap water and synthetic water are given in Table 4.

\subsection{Performance Evaluation of Augmented Coagulation System}

Performance evaluation of $F$. benghalensis as a bio-flocculant was assessed based on the removal of turbidity, NOM surrogates (i.e., DOC, $A_{254}, S U V A$ ), and spectral indices (i.e., ASI, $A_{272},-\Delta A_{272}$ ) from samples. During the coagulation experiment for alum and F. benghalensis, the $\mathrm{pH}$ was constant at $6 \mathrm{pH}$, and the dose was $2 \mathrm{mg} / \mathrm{L}$ for alum and $1 \mathrm{mg} / \mathrm{L}$ for $F$. benghalensis. In the case of augmented coagulation, only the dose of $F$. benghalensis was varied in the range of 1-4 mg/L, and its effect on coagulation activity was assessed.

Although, the efficiency of coagulants to remove suspended colloidal particulates or turbidity is the preliminary parameter to assess their coagulant activity but, it might be insufficient to insight into the variation in NOM characteristics during coagulation. The removal of dispersed particles using $F$. benghalensis, alum, and augmented coagulation from low turbid water have been shown in Fig. 3 (a). Alum has shown higher turbidity removal (11.12\%) than $F$. benghalensis (7.54\%) in low turbid water, which corresponds to the reported literature [25, 26]. The presence of charged ions could have allowed alum to attract dispersed negatively charged suspended particles, while, F. benghalensis reduced turbidity through sweep coagulation. However, a slight improvement in the

Table 4. Physiochemical Characteristics of Tap and Synthetic Water

\begin{tabular}{lccccccc}
\hline Physiochemical parameters & $\mathbf{p H}$ & Turbidity (NTU) & Zeta potential (mV) & DOC (mg/L) & TOC (mg/L) & $\mathbf{A}_{254}$ & SUVA \\
\hline Tap water & 7.88 & 7.4 & -0.7 & 20.52 & 22.61 & 0.0418 & 0.135 \\
Synthetic water & 6.0 & 10.0 & -30.0 & 24.50 & 25.76 & 0.7437 & 2.806 \\
\hline
\end{tabular}


turbidity removal was observed, when $F$. benghalensis was used as a bio-flocculant along with alum (at a dose of $2 \mathrm{mg} / \mathrm{L}$ of alum and $4 \mathrm{mg} / \mathrm{L}$ of $F$. benghalensis), about 13.14\% [Fig. 3 (b)]. Thus, it could be concluded that turbidity removal efficiency of augmented coagulation tend to be better at a higher dose of $F$. benghalensis due to the mutual effect of sweep coagulation and charge neutralization.

The increasing trend of total organic carbon in treated effluent using $F$. benghalensis as a coagulant and bio-flocculant has been shown in Fig. 3 (a) and (b). In the present study, the TOC removal efficiency of alum was estimated as $17.05 \%$, but in the case of F. benghalensis and augmented coagulation, TOC has been increased by $0.36 \%$ and $1.85 \%$, respectively, which could be due to higher dose of organic $F$. benghalensis (i.e., $4 \mathrm{mg} / \mathrm{L}$ in case of augmented coagulation). This minute increase in TOC could not be directly related to THMFP increment since this increment might be due to an increase in the hydrophilic fraction of NOM [54]. Similarly, Fooladvand et al. [55] have reported that with an increase in TOC from 3 to $7 \mathrm{mg} / \mathrm{L}$, the THMFP has increased from $50.04 \pm 5.53$ to $164.14 \pm 9.19 \mu \mathrm{g} / \mathrm{L}$.

Dissolved organic carbon is one of the prominent criteria for the assessment of the aromatic fraction of NOM in water as shown in Fig. 3 (a). The concentration of DOC increased by $10.2 \%$ in the effluent treated with $F$. benghalensis as a coagulant, which is due to an organic matrix of coagulant. However, alum imparted DOC removal efficiency to some extent ( $3.77 \%)$. A significant reduction in DOC was observed for augmented coagulation $(\sim 29.5 \%)$ at a dose of $2 \mathrm{mg} / \mathrm{L}$ of alum and $4 \mathrm{mg} / \mathrm{L}$ of $F$ benghalensis [Fig. 3 (b)]. In the case of augmented coagulation, the DOC removal was reduced with an increase in the dose of $F$. benghalensis, but at a higher dose, the DOC removal further increased. This result suggest that either alum will suppress the coagulant activity of $F$. benghalensis to reduce the DOC removal in treated water or combined effects of charge neutralization and sweep coagulation will support the DOC reduction. Similarly, Ramavandi et al. [56] have used DOC as an indicator for THM reduction.

Estimation of the UV absorbing fraction of NOM at the wavelength of $254 \mathrm{~nm}$ represents the extent of DOC and hydrophobic NOM present in water as shown in Fig. 3 (b) [24]. In the case of augmented coagulation, maximum removal of $\mathrm{A}_{254}$ absorbing materials was achieved (at the same dose of $2 \mathrm{mg} / \mathrm{L}$ alum and $4 \mathrm{mg} / \mathrm{L} F$. benghalensis) as compared to $F$. benghalensis and alum. $\mathrm{A}_{254}$ removal efficiency is low for $F$. benghalensis treated water due to an increase in the dissolved portion, mainly hydrophilic fraction. Still, in the case of augmented coagulation, removal efficiency has been increased due to rise in flocculation activity by adding bio-flocculant that causes the mutual effect of sweep coagulation and precipitate charge neutralization. Priya et al. [24] have also used the A254 to show the removal of hydrophobic NOM, which has good correlation with DOC reduction.

SUVA ( $=100 * \mathrm{~A}_{254} / \mathrm{DOC}$ ) represents the aromatic content, mainly hydrophobic fraction of NOM [24]. Fig. 3 (a) shows that SUVA reduction is more for $F$. benghalensis $(11.21 \%)$ as compared to alum $(3.61 \%)$ due to the removal of hydrophobic fractions. In the case of augmented coagulation system, SUVA value has increased by $16.36 \%$ [Fig. 3 (b)] due to more reduction in DOC value as compared to $\mathrm{A}_{254}$ value, there may also be the possibility of the reduction in the hydrophilic portion instead of a hydrophobic portion of DOC. It can be seen that SUVA value has been increased at all doses of alum and $F$. benghalensis.

Furthermore, the measurement of the coagulation activity of augmented coagulation system has been measured using spectral indices, as discussed below.

\subsection{Spectral Indices}

ASI represents the rate of changes of NOM absorbance as well as a reduction in DOC, which has a direct relation with THMFP and chlorine demand [34]. The ASI value also represents the apparent molecular weight fraction of NOM [10]. Fig. 3 (c) shows the declining trend of ASI from synthetic to treated water except for F. benghalensis treated water, and a lesser ASI value was observed for augmented coagulation. In the case of $F$. benghalensis, ASI has increased due to an increase in the hydrophilic fraction of DOC which validates the concept of augmented coagulation using aluminum sulphate and $F$. benghalensis for the control of trihalomethanes in chlorinated water.

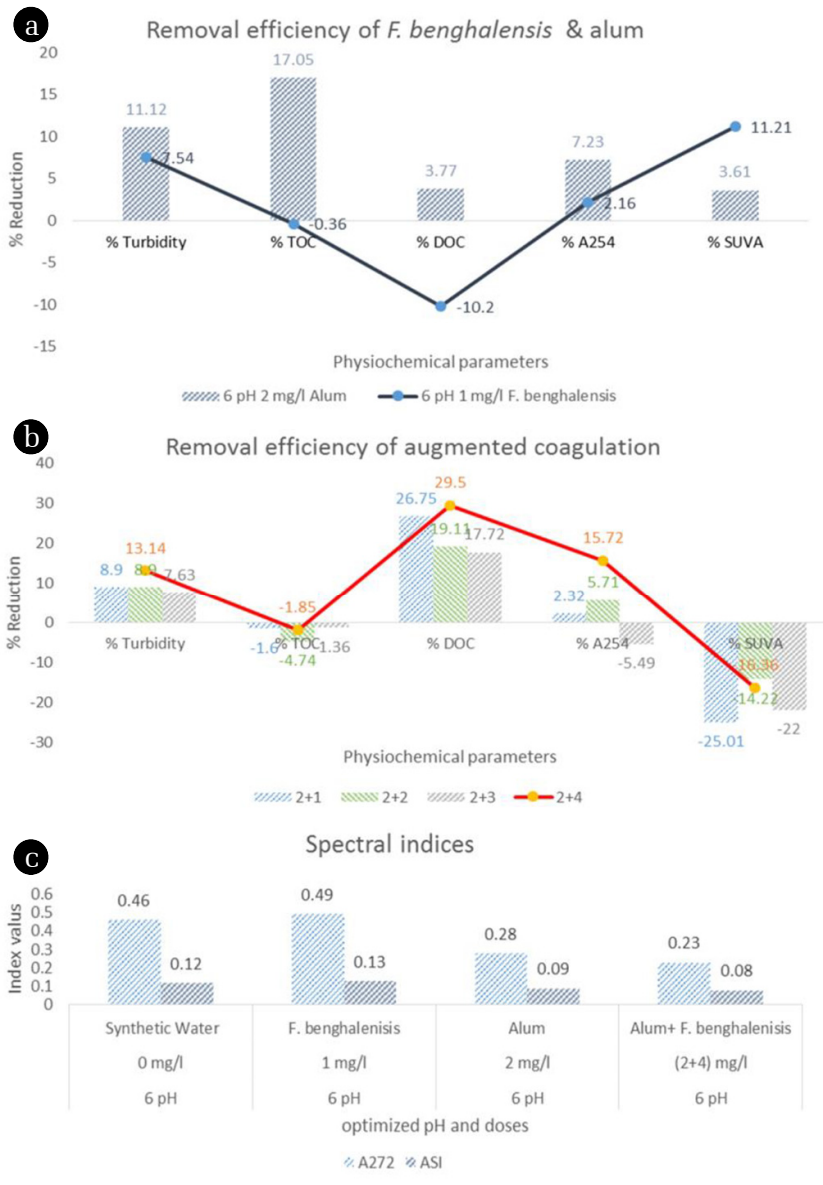

Fig. 3. (a) The removal efficiency of $F$. benghalensis and alum. (b) The removal efficiency of augmented coagulation (Alum $+F$. benghalensis). (c) Spectral indices (i.e. ASI \& $\mathrm{A}_{272}$ ) of raw and treated water. 
$\mathrm{A}_{272}$ shows the presence of activated aromatic groups responsible for disinfectant by-products formation potential [35]. Fig. 3 (c) shows that the $\mathrm{A}_{272}$ value is continuously decreasing from synthetic to treated water, except for $F$. benghalensis treated water. A maximum reduction in $A_{272}$ is observed for augmented coagulation system, so it can be stated that augmented coagulation is an efficient process to treat NOM enriched water. Similarly, Priya et al. [10] have used the spectral indices like ASI and A272 to show the reduction of active hydrophobic NOM fraction, which is responsible for the THMFP.

\subsection{Chlorine Demand and Differential Spectroscopy $\left(-\Delta \mathrm{A}_{272}\right)$}

The chlorine demand was estimated at an optimized $\mathrm{pH} 6$ as shown in Fig. 4 (a). The chlorine demand for synthetic water was estimated as $1.68 \mathrm{mg} / \mathrm{L}$ that is higher than the treated water, which could be due to the absence of anti-bacterial and disinfection agents. Fig. 4 (a), depicted that chlorine demand for F. benghalensis coagulated water $(1.5 \mathrm{mg} / \mathrm{L})$ is less than alum coagulated water $(1.55$ $\mathrm{mg} / \mathrm{L})$ due to the antibacterial activity of $F$. benghalensis. Least chlorine demand has been observed in augmented coagulation (1.4 mg/L), which might be due to the efficient removal of aromatic content as well as the antibacterial activity of $F$. benghalensis. The breakpoint chlorination curves for $F$. benghalensis, alum, and augmented coagulation has been shown in Fig. 4 (a).

Previous studies have demonstrated that differential spectroscopy $\left(-\Delta \mathrm{A}_{272}\right)$ has a definite correlation with DBPs formation on reaction with chlorine [41, 57]. Differential spectroscopy $\left(-\Delta \mathrm{A}_{272}\right)$ showing the chlorine consumption by treated water was performed as per the reported method [41]. From Fig. 4 (b), a linear relationship between chlorine doses and $-\Delta \mathrm{A}_{272}$ was observed in the effluent treated with alum and $F$. benghalensis, respectively, as a well significant drop in $-\Delta \mathrm{A}_{272}$ was observed for water treated using augmented coagulation system. That is mainly due to the combined effects of charge neutralization and sweep coagulation. F. benghalensis would promote higher rates of DBP formation as the value
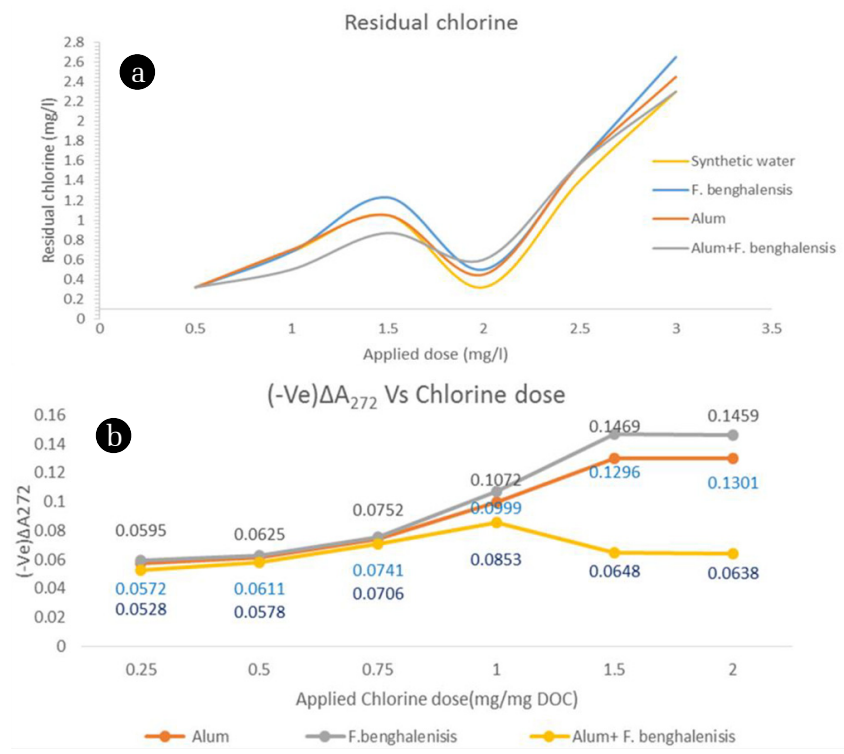

Fig. 4. (a) Break-point chlorination curve for synthetic and treated water. (b) $-\triangle \mathrm{A}_{272} \mathrm{Vs}$ Chlorine dose. of $-\Delta \mathrm{A}_{272}$ is increased than alum, possibly due to higher organic content in. F. benghalensis. But, the treatment of NOM enriched water using alum- $F$. benghalensis would mark a significant drop in DBP formation, which ascribes to the enhanced coagulation activity of the augmented coagulation system. Roccaro et al. [57] have also used differential spectroscopy $\left(-\Delta \mathrm{A}_{272}\right)$ to show the reduction of DBP formation potential, which has shown a good correlation with the DBPs reduction.

\section{Conclusions}

As, the direct removal of THMs is difficult, so the THM surrogates (i.e., aromatic NOM) has been targeted to be removed using coagulation process. Considering the inefficacy of the conventional coagulation process, an augmented coagulation technique has been proposed, in which the coagulation activity of the alum was increased using a novel bio-flocculant named $F$. benghalensis. The augmented coagulation system has shown a significant reduction of NOM surrogates (TOC, DOC, turbidity, $\mathrm{A}_{254}$, SUVA). The influence of $\mathrm{pH}$ and dose of coagulants was also correlated with the coagulation activity. The removal of aromatic NOM and subsequent THMFP reduction was further assessed by using spectral indices (ASI, $A_{272}$, $-\Delta A_{272}$ ), which are in good agreement with the removal of NOM surrogates. The spectroscopy, microscopy, and anti-bacterial analysis of $F$. benghalensis has also shown the amorphous nature, porous structure, presence of organic matrix, and disinfecting agents in it. These are responsible for the enhanced removal efficiency of the augmented coagulation system, lesser chlorine demand, and reduction in THMFP. The proposed augmented coagulation system can be widely used for the remediation of hydrophobic NOM from water.

\section{Acknowledgment}

The study was carried out within the research project (SR/S3/ CEE/00owledgement04/2013) funded by the Science and Engineering Research Board (SERB), Department of Science and Technology (DST), India. We would also like to thank the Department of Environmental Science and Engineering, Indian Institute of Technology (Indian School of Mines), Dhanbad, for providing financial support under the GATE fellowship funded by the Ministry of Human Resource Development (MHRD), the Government of India, Delhi.

\section{Author Contributions}

B.G. (M. Tech student) has performed the experimentation, analysis of water, physiochemical characterization of the coagulants and treated water, written the first draft of the manuscript, and finally reviewed and corrected the manuscript. T.P. (Ph.D. student) has helped in the experimentation, manuscript writing, and helped in reviewing and correcting the manuscript. B.K.M. (Assistant Professor) has supervised the work, helped in conceptualization, reviewed the manuscript and corrected it. 


\section{References}

1. Fabris R, Chow CWK, Drikas M, Eikebrokk B. Comparison of NOM character in selected Australian and Norwegian drinking waters. Water Res. 2008;42(15):4188-4196.

2. Samios SA, Golfinopoulos SK. Haloacetamides in the Drinking Water of Athens, Greece: Determination and Degradation. Anal. Lett. 2016;49(7):1091-1101.

3. Majumder A, Gupta B, Gupta AK. Pharmaceutically active compounds in aqueous environment: A status, toxicity and insights of remediation. Environ. Res. 2019;176:108542.

4. Kim H-C, Yu M-J. Characterization of natural organic matter in conventional water treatment processes for selection of treatment processes focused on DBPs control. Water Res. 2005;39(19):4779-4789.

5 Richardson PH, Willmer J, Foster TJ. Dilute solution properties of guar and locust bean gum in sucrose solutions. Food Hydrocoll. 1998;12(3):339-348.

6. Liu S, Lim M, Fabris R, Chow C, Drikas M, Amal R. Comparison of photocatalytic degradation of natural organic matter in two Australian surface waters using multiple analytical techniques. Org. Geochem. 2010;41(2):124-129.

7. Hong S. The Role of $\mathrm{pH}$ and Initial Concentration on GAC Adsorption for Removal of Natural Organic Matter. Environ. Eng. Res 1998;3(4):183-190.

8. Platikanov S, Tauler R, Rodrigues PMSM, Antunes MCG, Pereira D, Esteves da Silva JCG. Factorial analysis of the trihalomethane formation in the reaction of colloidal, hydrophobic, and transphilic fractions of DOM with free chlorine. Environ. Sci. Pollut. Res. 2010;17(8):1389-1400.

9. Priya T, Mishra BK. Enzyme Mediated Chloroform Biotransformation and Quantitative Cancer Risk Analysis of Trihalomethanes Exposure in South East Asia. Expo. Heal. 2017;9(1):61-75.

10. Priya T, Tarafdar A, Gupta B, Mishra BK. Effect of bioflocculants on the coagulation activity of alum for removal of trihalomethane precursors from low turbid water. J. Environ. Sci. 2018;70:1-10.

11. Bichsel Y, Gunten Uv. Oxidation of Iodide and Hypoiodous Acid in the Disinfection of Natural Waters. Environ. Sci. Technol. 1999;33(22):4040-4045.

12. Gallard H, A, Urs Von G. Chlorination of Phenols: Kinetics and Formation of Chloroform. Environ. Sci. Technol. 2002;36(5): 884-890.

13. Zazouli MA, Kalankesh LR. Removal of precursors and disinfection byproducts (DBPs) by membrane filtration from water; a review. J. Environ. Health Sci. Eng. 2017;15(1):1-10.

14. Korshin G, Yan M. Electrochemical dehalogenation of disinfection by-products and iodine-containing contrast media: A review. Environ. Eng. Res. 2018;23(4):345-353.

15. Ramavandi B, Dobaradaran S, Asgari G, Masoumbeigi H. High potential for the formation of haloacetic acids in the Karoon River water in Iran. Environ. Monit. Assess. 2013;185(5):37113720.

16. Ahmadi M, Ramavandi B. The formation potential of haloacetonitriles in the Dez River water, Iran. Environ. Technol. 2014;35(18):2347-2355.

17. Ramavandi B, Farjadfard S, Ardjmand M, Dobaradaran S. Effect of water quality and operational parameters on trihalomethanes formation potential in Dez River water, Iran. Water Resour. Ind. 2015;11:1-12.

18. Priya T, Prakash P, Mishra BK. Understanding the coagulant activity of zirconium oxychloride to control THMs formation using response surface methodology. Ecotoxicol. Environ. Saf. 2018;159:28-37.

19. Mishra B, Gupta S, Sinha A. Human health risk analysis from disinfection by-products (DBPs) in drinking and bathing water of some Indian cities. J. Environ. Health Sci. Eng. 2014;12(1):73.

20. Padhi RK, Subramanian S, Mohanty AK, Bramha SN, Prasad MVR, Satpathy KK. Trihalomethanes in the Cooling Discharge of a Power Plant on Chlorination of Intake Seawater. Environ. Eng. Res. 2012;17(S1):57-62.

21. Bhatnagar A, Sillanpää M. Removal of natural organic matter (NOM) and its constituents from water by adsorption - A review. Chemosphere 2017;166:497-510.

22. Sionkowska A. Current research on the blends of natural and synthetic polymers as new biomaterials: Review. Prog. Polym. Sci. 2011;36(9):1254-1276.

23. Jarvis P, Sharp E, Pidou M, Molinder R, Parsons SA, Jefferson B. Comparison of coagulation performance and floc properties using a novel zirconium coagulant against traditional ferric and alum coagulants. Water Res. 2012;46(13):4179-4187.

24. Priya T, Mohanta VL, Mishra BK. Performance evaluation of zirconium oxychloride for reduction of hydrophobic fractions of natural organic matter. Sep. Purif. Technol. 2017;174:104-108.

25. Šćiban M, Klašnja M, Antov M, Škrbić B. Removal of water turbidity by natural coagulants obtained from chestnut and acorn. Bioresour. Technol.2009;100(24):6639-6643.

26. Muthuraman G, Sasikala S. Removal of turbidity from drinking water using natural coagulants. J. Ind. Eng. Chem. 2014;20(4): 1727-1231.

27. Abebe LS, Chen X, Sobsey MD. Chitosan Coagulation to Improve Microbial and Turbidity Removal by Ceramic Water Filtration for Household Drinking Water Treatment. Int. J. Environ. Res. Public Health 2016;13(3):269.

28. Bazrafshan E, Mohammadi L, Ansari-Moghaddam A, Mahvi AH. Heavy metals removal from aqueous environments by electrocoagulation process - A systematic review. J. Environ. Heal. Sci. Eng. 2015;13(1):1-16.

29. Sonal S, Singh A, Mishra BK. Decolorization of reactive dye Remazol Brilliant Blue R by zirconium oxychloride as a novel coagulant: Optimization through response surface methodology. Water Sci. Technol. 2018;78(2):379-389.

30. Dearfield KL, Abernathy CO, Ottley MS, Brantner JH, Hayes PF. Acrylamide: its metabolism, developmental and reproductive effects, genotoxicity, and carcinogenicity. Mutat. Res. Genet. Toxicol. 1988;195(1):45-77.

31. Verma AK, Dash RR, Bhunia P. A review on chemical coagulation/flocculation technologies for removal of colour from textile wastewaters. J. Environ. Manage. 2012;93(1):154-68.

32. Ramavandi B, Hashemi S, Kafaei R. A novel method for extraction of a proteinous coagulant from Plantago ovata seeds for water treatment purposes. MethodsX 2015;2:278-282.

33. Bo X, Gao B, Peng N, Wang Y, Yue Q, Zhao Y. Coagulation performance and floc properties of compound bioflocculant-aluminum sulfate dual-coagulant in treating kao- 
lin-humic acid solution. Chem. Eng. J. 2011;173(2):400-406. 34. Korshin G, Chow CWK, Fabris R, Drikas M. Absorbance spectroscopy-based examination of effects of coagulation on the reactivity of fractions of natural organic matter with varying apparent molecular weights. Water Res. 2009;43(6):1541-1548.

35. Li C-W, Korshin GV, Benjamin MM. Monitoring DBP formation with differential UV spectroscopy - ProQuest. J. Am. Water Works Ass. 1998;90(8):88-100.

36. Sohn J-S, Kang H-S, Han J-H, Yoon Y-M. Change of Molecular Weight of Organic Matters through Unit Water Treatment Process and Associated Chlorination Byproducts Formation. Environ. Eng. Res. 2007;12(5):224-230.

37. Ndabigengesere A, Narasiah KS, Talbot BG. Active agents and mechanism of coagulation of turbid waters using Moringa oleifera. Water Res. 1995;29(2):703-710.

38. Ndabigengesere A, Subba NK. Quality of water treated by coagulation using Moringa oleifera seeds. Water Res. 1998;32(3):781791.

39. Holder IA, Boyce ST. Agar well diffusion assay testing of bacterial susceptibility to various antimicrobials in concentrations non-toxic for human cells in culture. Burns 1994;20(5):426-429.

40. Rice EW, Baird RB, Eaton AD, Clesceri LS. 22nd ed. editors. Standard methods for the examination of water and wastewater. APHA; 2012.

41. Korshin GV, Wu WW, Benjamin MM, Hemingway O. Correlations between differential absorbance and the formation of individual DBPs. Water Res. 2002;36(13):3273-3282.

42. Sarkar AK, Saha A, Tarafder A, Panda AB, Pal S. Efficient Removal of Toxic Dyes via Simultaneous Adsorption and Solar Light Driven Photodegradation Using Recyclable Functionalized Amylopectin- $\mathrm{TiO}_{2}-\mathrm{Au}$ Nanocomposite. ACS Sust. Chem. Eng. 2016;4(3):1679-1688.

43. Gupta B, Gupta AK, Ghosal PS, Tiwary CS. Photo-induced degradation of bio-toxic Ciprofloxacin using the porous 3D hybrid architecture of an atomically thin sulfur-doped g-C3N4/ZnO nanosheet. Environ. Res. 2020;183:109154.

44. Sonal S, Prakash P, Mishra BK, Nayak GC. Synthesis, characterization and sorption studies of a zirconium(IV) impregnated highly functionalized mesoporous actIVated carbonsb. RSC Adv. 2020;10(23):13783-13798.

45. Araújo CST, Alves VN, Rezende HC, Coelho NMM. Development of a flow system for the determination of low concentrations of silver using Moringa oleifera seeds as biosorbent and flame atomic absorption spectrometry. Microchem. J. 2010;96(1):8285.
46. Lou J-C, Chang C-J, Chen W-H, Tseng W-B, Han J-Y. Removal of Trihalomethanes and Haloacetic Acids from Treated Drinking Water by Biological Activated Carbon Filter. Water Air Soil Pollut. 2014;225(2):1851.

47. Jung WK, Koo HC, Kim KW, Shin S, Kim SH, Park YH. Antibacterial activity and mechanism of action of the silver ion in Staphylococcus aureus and Escherichia coli. Appl. Environ. Microbiol. 2008;74(7):2171-2178.

48. Ghaedi M, Yousefi-Nejad M, Safarpoor M, et al. Synthesis of $\mathrm{CuS}$ nanoparticles and evaluation of its antimicrobial properties in combination with Linum usitatissimum root and shoot extract. Desalin. Water Treat. 2016;57(51):24456-24466.

49. Ramavandi B. Treatment of water turbidity and bacteria by using a coagulant extracted from Plantago ovata. Water Resour. Ind. 2014;6:36-50.

50. Palermo EF, Kuroda K. Structural determinants of antimicrobial activity in polymers which mimic host defense peptides. Appl. Microbiol. Biotechnol. 2010;87(5):1605-1615.

51. de Freitas RA, Drenski MF, Alb AM, Reed WF. Characterization of stability, aggregation, and equilibrium properties of modified natural products; The case of carboxymethylated chitosans. Mater. Sci. Eng. C 2010;30(1):34-41.

52. Solomonidou D, Cremer K, Krumme M, Kreuter J. Effect of carbomer concentration and degree of neutralization on the mucoadhesive properties of polymer films. J Biomater Sci Polym Ed 2001;12(11):1191-205.

53. Yang ZL, Gao BY, Yue QY, Wang Y. Effect of $\mathrm{pH}$ on the coagulation performance of Al-based coagulants and residual aluminum speciation during the treatment of humic acid-kaolin synthetic water. J. Hazard. Mater. 2010;178(1-3):596-603.

54. Klymenko NA, Samsoni-Todorova EA, Savchina LA. The influence of natural organic matter on trihalomethanes formation during the conditioning of drinking water. J. Water Chem. Technol. 2016;38(6):353-357.

55. Fooladvand M, Ramavandi B, Zandi K, Ardestani M. Investigation of trihalomethanes formation potential in Karoon River water, Iran. Environ. Monit. Assess. 2011;178(1-4):63-71.

56. Ramavandi B, Farjadfard S, Ardjmand M. The correlation of trihalomethanes with other disinfections by-products and fractionation of dissolved organic carbon in Dez River water. J. Water Chem. Technol. 2017;39(3):181-184.

57. Roccaro P, Chang H-S, Vagliasindi FGA, Korshin GV. Differential absorbance study of effects of temperature on chlorine consumption and formation of disinfection by-products in chlorinated water. Water Res. 2008;42(8-9):1879-1888. 